\title{
An Update on Rodent Model Studies in Diabetic Neuropathy: a Brief Communication
}

\author{
Nadia Nara Rolim Lima1, \\ Carlos Augusto Carvalho Vasconcelos ${ }^{2}$, \\ Antonio Gilvan Teixeira Júnior ${ }^{3,4}$, \\ Lorenza Andres Almeida de Souza 4,5 \\ Marcos Antonio Pereira de Lima ${ }^{3}$, Randy Alan Nessler 6 , \\ Marcelo Moraes Valença7
}

\section{Abstract}

The diseases of the peripheral nerves are quite common and diversified, are directly related to several factors, ranging from the imbalance related to good nutrition and adequate needs of nutrients, going to the injuries caused by drugs or mechanisms external to the human organism. Diabetes is a complex syndrome that affects and kills millions of people worldwide. We demonstrated through the experimental model of diabetes using STZ@ in single intraperitoneal dose of $60 \mathrm{mg} / \mathrm{kg}$, that both a purely motor nerve can be directly affected as well as a special afferent nerve (cranial nerve), this comparison showed us that there is a possibility of having a new type of mixed type neuropathy, this may be related to the amount of the dose involved, such as the time of disease progression, but more studies need to be done for definitive confirmation. We can extrapolate the original results to understand the mechanisms of diabetes in humans, although it does not yet have an experimental model of type II diabetes, more related to eating disorders, the STZ application simulates the effects of type I or insulin dependent diabetes, with more serious and deleterious effects mainly the more distal portions of the nerves. Prevention and food control are very important, especially those related to the mechanisms that involve carbohydrate metabolism and its peripheral resistance. The original results commented here are relevant for the continuous study of this serious but old illness, but quite current in the medical and therapeutic clinic.
1 Fellow of the PNPD Program/CAPES Institutional POSNEURO/Federal University of Pernambuco (UFPE), Recife, Pernambuco, Brazil.

2 Department of Nutrition/LNED and Electronic Microscopy Division of LIKA - CCS/Federal University of Pernambuco (UFPE), Recife, Pernambuco, Brazil.

3 Faculty of Medicine, Federal University of Cariri. Barbalha, Ceará, Brazil.

4 Science without Borders fellow at University of Liverpool, Liverpool, United Kingdom.

5 Bahiana School of Medicine and Public Health, Salvador, Brazil.

6 Director of the Central Microscopy Research Facility, The University of lowa, lowa City, IA, USA.

7 PNPD Program/CAPES Institutional POSNEURO/Federal University of Pernambuco (UFPE), Recife, Pernambuco, Brazil.

\section{Contact information:}

\section{Carlos Augusto Carvalho de} Vasconcelos.

Address: Department of Nutriton/ LNED and Electron Microscopy division of the LIKA. UFPE, Federal University of Pernambuco, Recife, Brazil.

झ"vasconcelos984@gmail.com

\section{Keywords}

Experimental Model of Diabetes; Sensory and Motor Peripheral Nerves; Peripheral Nerve Injuries; Neuropathies; STZ; Rats. 


\section{Introduction}

Nearly 387 million people have diabetes worldwide, and this epidemic disease continues to rise at an alarming rate, being expected 552 million by 2030 . $[1,2,11,14]$ Type 2 diabetes mellitus (T2DM) accounts for $95 \%$ of diagnosed diabetes, $[2,3]$ and its complications, including heart disease and stroke, result in significant morbidity and mortality, representing the first and fourth most common causes of death, respectively, in the U.S. $[2,3]$

Diabetes mellitus (DM) is the most common metabolic disease with a high prevalence rate in human society that eventually leads to the peripheral nervous system complications in a great number of patients. It is a chronic metabolic disorder that leads to long-term complications affecting some sites such as heart, kidney, retina, vessels and peripheral nerves. [4, 5, 10] Peripheral neuropathy is one of the common complications of diabetes which in turn increases the risk of other diabetes complications such as foot ulcers and amputation. [6, 7, 10] Almost more than half of diabetic patients suffer from different forms of neuropathy after passing 1-2 decades of their diseases. [8, 10] Abnormalities of polyol pathway and defects of protein kinase $C$ metabolism which cause nerve demyelination have also been described in diabetic peripheral neuropathy. $[9,10]$ Based on these mechanisms of injury, various prevention and treatment strategies have been already suggested and are under investigation. [10]

As mentioned before, peripheral neuropathies are a major cause of morbidity in patients with diabetes mellitus, affecting as many as $50 \%$ of patients with diabetes. $[12,14]$ They can cause acute and chronic neuropathic pain, hyperalgesia and impaired nerve conduction velocities, which can cause significant morbidity of these patients and affect their daily activities. [13, 14]

There are two main types of DM. Type 1 DM (T1DM) results from the body's failure to produce insulin and type 2 DM (T2DM) results from insulin resistance, where cells fail to use insulin properly, sometimes combined with an absolute insulin deficiency. An increase in blood glucose levels represents a recognized diagnostic criterion for diabetes. [15] The best predictor of T2DM macrovascular complications is the preceding presence of microvascular complications, particularly diabetic polyneuropathy (DPN) and diabetic nephropathy (DN). [2]

DPN consists of demyelization and axonal degeneration of peripheral nerves, [16], leading to slowing of nerve conduction velocity and reduction of the amplitude of the compound muscle and sensory nerve action potentials. [16, 23] These features of diabetic polyneuropathy are observed in human diabetes $[16,24]$ and in experimentally induced diabetic animals. [17-23]

DPN is one of the main complications of diabetes, which may impair the peripheral nerve regeneration. Though the causes for failed regeneration in diabetic peripheral nerves are not completely elucidated, possible etiopathologies have been reported, such as structural changes in peripheral blood vessels and reductions in blood flow, $[25,54]$ delays in recruitment of macrophages to clean degrading myelin in injured peripheral nerve fibers, [26, 54] and reductions in neurotrophic supports for nerve tissue regeneration. $[27,54]$

DPN is not a single entity, but encompasses several neuropathic syndromes, including sensory and motor defects. A wide variety of sensorimotor symptoms which affects approximately $50 \%$ of diabetic patients is presented by patients with DPN. Changes in the neural circuits may occur in the early stages in diabetes and are implicated in the development of DPN. [28]

Early physiological disorders such as nerve conduction slowing and sensory loss can be used to diagnose and stage diabetic neuropathy, [29, 34] and may predict the onset of degenerative changes in neurons, Schwann cells and blood vessels. Nerve biopsy studies have described segmental demye- 
lination and axonal degeneration of large fibers as common features of nerve pathology, $[30,34]$ while the use of skin biopsies and corneal confocal microscopy has emphasized the early damage of small sensory fibers terminals. [31, 34] The two dominant risk factors for diabetic neuropathy are poor glycemic control and duration of diabetes which are widely appreciated $[32,34]$ Other risk factors for neuropathy that emerge after correcting the hyperglycemia include increased plasma triglyceride levels, body-mass index, smoking and hypertension. $[33,34]$

\section{Methods}

Despite considerable researches on DPN, evidence for pathophysiological changes in the nervous systems underlying the impairment of motor function still lacks neurostructural evidence. Previous studies have focused on the role of peripheral nerves in DPN. Increasing evidence now indicates that the onset of DPN might be in all levels of the nervous system, including both the Peripheral Nervous System (PNS) and the Central Nervous System (CNS). $[28,35,36,39]$ Although the involvement of both PNS and CNS in DPN has previously been recognized, the underlying mechanisms remain poorly understood, particularly in the changes of the neural circuits between spinal nerves and spinal cord via the Dorsal Root Ganglia (DRG) and ventral root. Thus, investigating the alterations in the neural circuits is essential for understanding the development of the sensory and motor defects in DPN. It is important remember that the spinal nerves conduct mixed signals, including sensory and motor information from nerve endings in the PNS, [28, 37] And finally, that the various types of DRG neurons send their central axonal processes to different parts of the spinal dorsal horn in the CNS. [28, 37, 38]

Several morphometric studies have demonstrated abnormalities of the myelinated and unmyelinated fibers in painful DPN. [15, 39, 40, 41, 42]. Equally, a significant loss in dermal fiber density was observed in preclinical models of diabetes.[15] Besides, the mechanical response properties of spinal neurons have been shown to be altered in different models of neuropathic pain, including DPN. [15, 43, 44]

Results have shown that the neuronal basis of diabetes-induced neuropathic pain might differ across models. This demonstrates the complexity of the neuronal reorganization following hyperglycemiainduced neuronal damage and the resulting challenge for an effective treatment of diabetes-based neuropathic pain. [15]

Different models for diabetic neuropathy in the rat have demonstrated distinct response properties of spinal wide dynamic range (WDR) neurons. This specificity in electrophysiological properties of WDR neurons for every investigated model might reflect differences in the pathological mechanisms in pain transmission and also suggest substantial differences underlying diabetes-induced neuropathic pain in T1DM and T2DM, as well as between chemicallyinduced and genetically determined diabetic rats. These differences are most likely due to a variety in metabolic changes, pathology, disease progression as well as severity and duration of diabetes. It can be assumed that, depending on the severity and duration of diabetes, it is the degree of spinal reorganization, due to the degeneration of small afferents, for example, which leads to the deafferentation of spinal neurons and the abnormal branching of $A-b$ fibers. [16, 45, 47]

Moreover, the anatomical framework of the spinal cord allows the transfer of specific inputs to localized subsets of dorsal horn neurons. This allows the separation in signal transduction pathways for low-intensity stimuli and noxious stimuli. The structural reorganization on the level of the spinal cord might contribute to the development of the pain. $[15,45,46]$

The different mechanisms involved in different pain sensations are still poorly understood. Especially 
in a complex and diverse disease as DPN, the plastic reorganization processes of the somatosensory system along the pain pathway need further detailed investigation. It was detected complex alterations in spinal neuronal response properties of hyperglycemic rats, which varied significantly depending on stimulus force and quality. The electrophysiological technique allows a very detailed qualitative characterization of neuronal hyperexcitability, in specific diabetes models that complement the behavioral findings. These data reveal that specific neuronal properties can be associated with behavioral sensory abnormalities measured by evoked response studies in conscious rats. [15]

Pharmacological treatments have been used to accelerate regeneration of peripheral diabetic nerves, such as angiotension II type 1 receptor blockers, $[47,54]$ neurotrophic factors and anti-apoptotics. $[48,54]$ Recent studies have also shown that herbal medicine may be an alternative treatment for neuronal repair and regeneration in diabetic peripheral neuropathy. [49, 54] As for nonpharmacological approaches, a number of studies have reported the efficacy of various electrotherapies on regenerating diabetic nerves, such as electro-magnetic fields, [50, 54] transcutaneous electrical stimulation [51, 54] and percutaneous electrical stimulation. [52, 54] Of all these electrotherapies, the percutaneous electrical stimulation not only can be precisely placed on muscles or nerves, but it is also safe with rare complications. [53, 54]

\section{Results}

The emerging clinical recognition of multiple risk factors associated with diabetic neuropathy has not been widely explored in animal models, where a reductionist approach has largely been adopted and a glucocentric view of pathogenic mechanisms has historically dominated [34, 55]. This approach is consistent with the primary risk factors for human diabetic neuropathy and the widely studied streptozotocin (STZ) model of type 1 diabetes replicates a number of features of diabetic neuropathy such as large fiber conduction slowing, sensory dysfunction and depletion of unmyelinated epidermal nerve fibers in the skin [34, 56, 57] STZdiabetic rodents are less successful at modeling the degenerative pathology of myelinated fibers. The most widely and consistently reported structural disorder in nerve trunks of STZ-diabetic rats is reduced axonal caliber of myelinated fibers [20, 35, $58,59]$ while degenerative pathology occurs in the most distal nerves of STZ-diabetic mice only after many months of hyperglycemia. [34, 60]

The absence of more dramatic nerve pathology is frequently attributed to the relatively short durations of hyperglycemia attainable in rodent models of diabetes. Direct investigation of the pathogenesis of segmental demyelination has been particularly impeded by the absence of Schwann cell and myelin pathology in the common models of diabetic neuropathy, and a considerable leap of faith is necessary when attempting to translate therapeutics from preclinical models to clinical trials. [34]

Simalary to Gregory JA et al [34], we conducted a small experiment in order to show the degenerative pathology in distal nerves of STZ-diabetic induced [4] rats caused by the hyperglycemia. We used 12 male Wistar rats $(n=12)$ at 42 days of age. They were induced to become diabetic with streptozotocin (STZ) [4]. Half of these animals $(n=6)$ were fasted for 12 hours prior to being injected intraperitoneally with STZ $(60 \mathrm{mg} / \mathrm{kg})$ in a single dose. Control animals $(n=6)$ received vehicle. Ten weeks after STZ injection the animals were perfused intracardially with Karnovsky solution. Right and left sciatic nerves were dissected and processed for epoxy resin embedding. Samples were imaged with a transmission electron microscope. Compare the control group nerves (Figure 1) with nerves of STZdiabetic induced rats (Figure 2). These results were presented at the Expeirmental Biology Congress in Boston, USA, 2013. 
Figure 1 A-D: Electron micrographs of transverse sections of the sciatic nerve of control Wistar rat, presenting a well organized endoneurium. Note the presence of large and small myelinated fibers, with uniform myelin sheath enveloping the axon. Clustering of unmyelinated axons surrounded by Schwann cells profiles are also present. The Schwann cell nucleus are noticeable through its close relationship to the myelinated or unmyelinated axons. Note the presence of several mitochondria in the axoplasm.
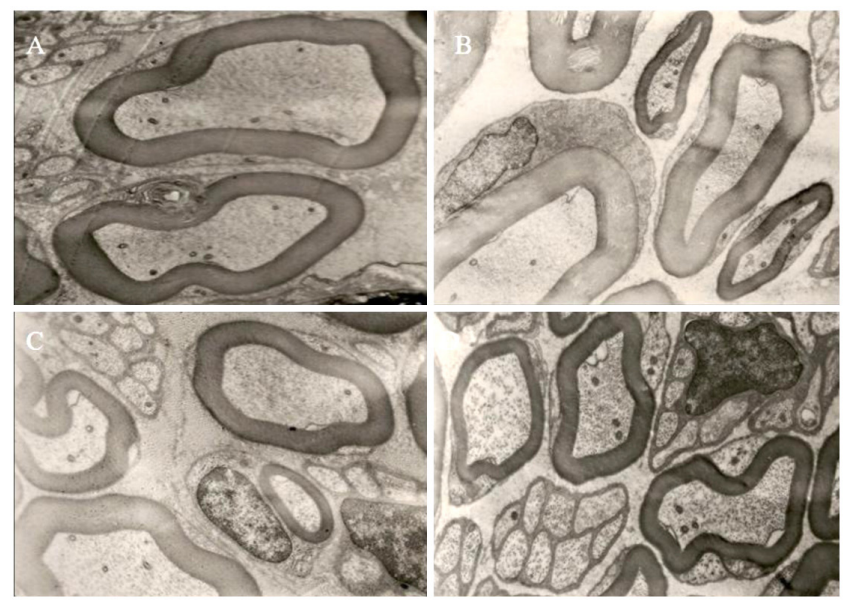

Magnification: $A, B, C=x 10,000$ and $D=x 6,700$.

Although diabetic neuropathy more commonly affects the peripheral nerves $[35,61]$, or the optic nerve, and the autonomic fibers, hyperglycemia can also cause damage to other cranial nerves, such as the vestibulocochlear, shown by us in Figure $\mathbf{3}$.

Schwann cell metabolism is certainly compromised by diabetes, [34, 61, 70] as indicated by depletion of nerve ciliary neurotrophic factor (CNTF) levels, [34, 62, 63] but myelin thickness, structure and ultrastructure are preserved when viewed in appropriately fixed tissue. Speculation as to why demyelination does not develop in diabetic rodents has frequently evoked the short absolute duration of exposure to diabetes in rats when compared to humans. [3]
Figure 2 A-F: Representative electron-micrographs of the sciatic nerve of chronic STZ-induced diabetic rats.

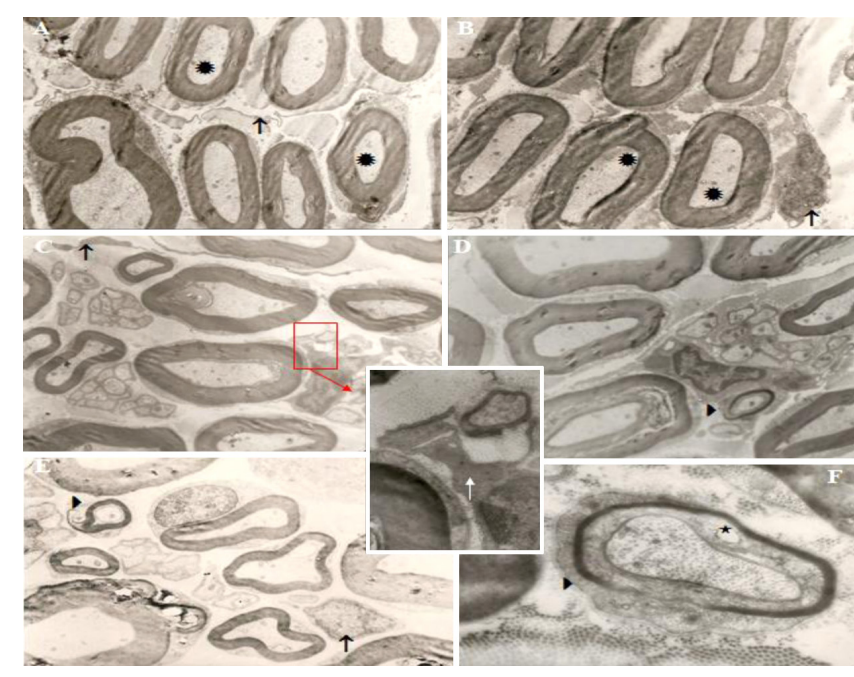

A-B) Asterisks show axonal atrophy of large myelinated fibers and arrows show fibroblast profiles in $A$ and fibroblast nucleus in $B . \times 4,000$. C) Suggestive image of a macrophage in the endoneurium, involving an unmyelinated fibers with their pseudopods. $x 4,000$. In large magnification, the insertion in the center shows a pseudopod involving an unmyelinated fiber and a giant mitochondria shown by the white arrow. $\times 27,000$. D) Note the thin myelinated fibers showing signs of demyelination. $x 5,000$. E) Another thin fiber demyelination image $\times 5,000$. F) Note in high magnification, a thin fiber demyelination (arrowhead) and the presence of a vacuole in the myelin sheath. $\times 20,000$.

Figure 3: Electron micrographs of transverse sections of the vestibulocochlear nerve in STZ-diabetic induced rats. Note the presence of myelin folds and axonal atrophy, marked by asterisks.

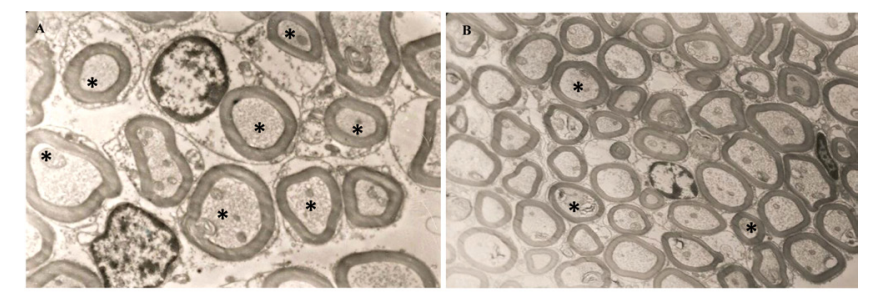

A) $\times 5,000$ and in smaller size the image shows the same results $\times 2,700$ (B).

Diabetic rats develop slowing conduction on large fiber within weeks of onset of hyperglycemia that is initially reversible and has a metabolic pathogenesis. $[35,65,66]$ A reduction in axonal caliber can be detected after 2-3 months of diabetes and contributes to progressive conduction slowing [34, 
58, 59, 66] However, rodent models of diabetic neuropathy are frequently faulted as showing little reliable evidence of overt structural damage to myelinated fibers such as the segmental demyelination, remyelination and Wallerian degeneration that characterizes human diabetic neuropathy. [34, 67] The resilience of myelin in diabetic rodents is surprising given the metabolic stress placed on Schwann cells by hyperglycemia-driven flux through aldose reductase. [34, 68, 69]

Acute nerve conduction velocities (NCV) slowing reported in other STZ-diabetic rat strains has been attributed to nerve ischemic hypoxia. $[35,71]$ It is notable that reductions in nerve blood flow (23\%) and conductance (20\%) after 6 months of STZinduced diabetes in WKY rats were substantially less than the $50 \%$ decrease widely reported to occur following 2-4 weeks of diabetes in other strains using a variety of techniques. [34, 71-73] Reduced nerve blood flow after 6 months of diabetes in WKY rats was associated with a $29 \%$ reduction in endoneurial blood vessel number. A slowly developing vasculopathy may contribute to reduced nerve blood flow in this strain. In general, STZ-diabetic WKY rats lacked the dramatic early nerve conduction slowing reported in other strains and displayed a slowly evolving impairment of conduction accompanied by loss of endoneurial blood vessels and reduced axonal radial growth. [34]

SHR rats are hyperactive, [36, 74] and findings of reduced body weight and plasma insulin levels compared to WKY rats were consistent with prior reports. [34, 75, 76] SHR rats also showed progressively developing NCV deficits and attenuated axonal radial growth in the sciatic and sural nerves, without myelinated fiber loss or any change in fiber density. These features have been previously reported, $[34,77]$ along with generalized myelin thinning in formalin-fixed paraffin embedded sections. [34]

Axons with disproportionately thin myelin sheaths were observed, while not sufficiently frequent to impact the average myelin thickness of all fibers in the nerve cross section, and they were more frequent in nerves from SHR rats than in age-matched WKY rats. Identification of supernumerary Schwann cell processes encircling thinly myelinated fibers reflects demyelination and subsequent remyelination. [34, 78, 79] Similar profiles are seen in nerve from diabetic patients [34, 67, 68] and can cause conduction slowing independent of axonopathy. [34, 80] Although the proportion of thinly myelinated fibers was low, each cross section analyzed illustrates one of approximately 50 Schwann cells that myelinate an axon along its length, assuming a nerve of $5 \mathrm{~cm}$ length and an intermodal distance of $1 \mathrm{~mm}$. [34, 81] Myelin disorders are equally infrequent in cross sections of nerves from patients with neuropathy. [34, 80] It is not clear yet if myelin thinning persists along the entire length of occasional axons or if it is intermittently segmental along the length of many fibers. If the latter occurs, up to $10 \%$ of all fibers within the sciatic nerve could be affected at some position $(0.2 \%$ in one crosssection $\times 50$ potential internodes). Teased fiber studies may resolve this issue. Early NCV slowing in SHR rats may reflect segmental demyelination and partial remyelination, whereas the later period of attenuated NCV increase also includes a contribution from restricted axonal maturation. The findings support the suggestion that hypertension can promote peripheral neuropathy and serve as an independent risk factor for neuropathy in diabetic patients. [34, 82-86]

Current murine data suggest that both elevated cholesterol and obesity may be particularly instrumental in inciting nervous system damage. Some authors contend that dyslipidemia and visceral adiposity in males form a network with insulin resistance, hypertension, and hyperglycemia to injure the peripheral nervous system, particularly myelinated large fibers. These murine data support that this network of metabolic impairments activates detrimental feed-forward cycles of local and systemic 
oxidative stress and dysregulated energy homeostasis with local mitochondrial dysfunction and inflammation, thus resulting in neural injury and DPN. Corroborating this idea, there are some clinical studies showing that dyslipidemiais strongly correlated with DPN $[2,87]$ and that lowering cholesterol, not glycemia, is significantly associated with decreasing lower-extremity amputations among patients with diabetes $[2,88]$.

In summary, the glycemic control alone is not sufficient to ameliorate injury to large myelinated fibers in murine models of T2DM and DPN, likely because of the persistence of hypercholesterolemia as well as local neural dysfunctional lipoprotein signaling. These findings along with similar results in several large clinical trials in patients with T2DM and DPN collectively suggest that treatment of the metabolic syndrome as a whole and not just hyperglycemia is required to effectively target DPN in T2DM. [2]

\section{Conclusion}

Impaired myelinated axon population of peripheral nerves as a consequence of regenerative failure has been clearly seen in the rat model of diabetes. [54, $89,90]$ It could be caused by slow infiltration of endoneurial macrophages, delaying Wallerian degeneration and subsequent nerve regeneration. Another possibility that the regenerative deficit is related to decreased action of vasoactive neuropeptides such as calcitonin gene-related peptide (CGRP) in diabetics which may render an ischaemic environment in nerve microvessels following nerve injury. [26, 54]

Percutaneous electrical stimulation (ES) of $1 \mathrm{~mA}$ or above was suggested as possible inductor of a transient rise in skin perfusion in diabetic rats, restoring the blood circulation that is essential for stimulation of these regenerative processes. As seen in the medical literature, it was found that diabetes has caused a slowdown in NCV and latency in rats, which are similar to the early neuropathic changes in diabetic patients. $[54,98,99]$ The data demonstrated that ES treatment, especially at $10 \mathrm{~mA}$, could produce profound improvements in NCV and latency in the diabetic rats. [54]

Count and density of myelinated axons in the mid-portion of regenerated sciatic nerves showed to be dramatically decreased in the diabetic groups compared to those in the non diabetic normal animals. The vestibulocochlear nerve, a special afferent nerve is also directly affected, perhaps because of its rich vascularization and immense fiber density. Several authors have reported similar results that rats with diabetes usually have a decreased rate of nerve regeneration. [47, 54, 93] However, the reduced regeneration rate after axotomy in diabetes was elevated in the rats as they received ES treatment at $10 \mathrm{~mA}$ or or above. This improvement is thought to be due to these aforementioned ES's positive effects, i.e., accelerated circulatory blood flow, increased expression of CGRP, or improved macrophage infiltration in the diabetic nerves. [54] We must continue with more studies to try to elucidate several questions still in studies, the experimental model of diabetes only represents the effect of type I diabetes, type 2 diabetes related to feeding and metabolism of carbohydrate is still more compelling still and does not have an experimental model yet .

\section{Acknowledgments}

We are thankfull to the Laboratory of Immunopathology Keizo Asami, Federal University of Pernabuco (LIKA/UFPE) for supporting us; To Mr. Rafael Padilha for his excellent help. We are also very grateful to the National Council for Scientific and Technological Development (CNPq). We would also like to the Scientific Writing Lab (LABESCI) - Federal University of Cariri (UFCA). This manuscript is dedicated to titular professor of Faculty of Medicine of Ribeirão Preto/University of São Paulo (FMRP/USP), Júlio César Voltarelli deceived in 
2012, pioneer in research with stem cells for the treatment of autoimmune diseases, such as type 1 diabetes in Brazil.

\section{Conflict Of Interest}

The authors declare no conflicts of interest

\section{Role Of Funding Source}

PNPD/CAPES INSTITUTIONAL, Federal University of Pernambuco, UFPE (Process number: 2311/2011). Nádia Nara Rolim Lima received a scholarship from PNPD/CAPES INSTITUTIONAL, PROPESQ/UFPE of the POSNEURO Program.

\section{References}

1. Robertson DM, Sima AA. Diabetic neuropathy in the mutant mouse [C57BL/ ks(db/db)]: a morphometric study. Diabetes 1980; 29:60-67.

2. Hur J et at. The Metabolic Syndrome and Microvascular Complications in a Murine Model of Type 2 Diabetes. Diabetes. 2015 Sep; 64(9):3294-304

3. Centers for Disease Control and Prevention. National Diabetes Statistics Report: Estimates of Diabetes and Its Burden in the United States, 2014. Atlanta, GA, U.S. Department of Health and Human Services, 2014

4. Zangiabadi N., Asadi-Shekaari M., Sheibani V., et al. Date fruit extract is a neuroprotective agent in diabetic peripheral neuropathy in streptozotocin-induced diabetic rats: a multimodal analysis. Oxidative Medicine and Cellular Longevity. 2011; $2011: 9$.

5. Gallieni M., Aiello A., Tucci B., et al. The burden of hypertension and kidney disease in northeast India: the institute for indian mother and child noncommunicable diseases project. The Scientific World Journal. 2014; 2014:6

6. Belchetz P., Hammond P. J. Mosby's Color Atlas and Text of Diabetes and Endocrinology. Edinburgh, UK: Mosby; 2003.

7. Houreld N. N. Shedding light on a new treatment for diabetic wound healing: a review on phototherapy. The Scientific World Journal. 2014; 2014:13.

8. Lederman R. J. Bradley's neurology in clinical practice. JAMA 2012; 308(16):p. 1694

9. Tanenberg R. J. Diabetic peripheral neuropathy: painful or painless. Hospital Physician.2009; 45(7):1-8.

10. Zangiabadi $\mathrm{N}$ et al. The effect of Angipars on diabetic neuropathy in STZ-induced diabetic male rats: a study on behavioral, electrophysiological, sciatic histological and ultrastructural indices. Scientific World Journal. 2014; 2014:721547.
11. Whiting DR, Guariguata L, Weil C, Shaw J. IDF diabetes atlas: global estimates of the prevalence of diabetes for 2011 and 2030. Diabetes Res ClinPract. 2011; 94:311-321. [

12. Didangelos T, Doupis J, Veves A. Painful diabetic neuropathy: clinical aspects. HandbClin Neurol. 2014; 126:53-61.

13. Schreiber AK, Nones CF, Reis RC, Chichorro JG, Cunha JM. Diabetic neuropathic pain: Physiopathology and treatment. World J Diabetes. 2015; 6:432-444

14. Li $\mathrm{M}$ et al. Luteolin improves the impaired nerve functions in diabetic neuropathy: behavioral and biochemical evidences. Int J Clin Exp Pathol. 2015 Sep 1; 8(9):10112-20. eCollection 2015.

15. Schuelert $N$ et al. Electrophysiological characterization of spinal neurons in different models of diabetes type 1- and type 2-induced neuropathy in rats. Neuroscience. 2015 Apr 16; 291:146-54.

16. TimperleyWR, BoultonAJM, Davies-Jones GAB, Jarratt JA, Ward JD. Small vessel disease in progressive diabetic neuropathy associated with good metabolic control. J ClinPathol. 1985; 38:1030-8

17. Brussee V, Cunningham $A$, ZochodneDW. Direct insulin signaling of reverses diabetic neuropathy. Diabetes. 2004; 53:1824-30.

18. Drel VR, Mashtalir N, Inytska O, Shin J, Li F, Lyzogubov VV, Obrosova IG. The leptin-deficient (ob/ob) mouse: A new animal model of peripheral neuropathy of type 2 diabetes and obesity. Diabetes. 2006; 55:3335-43.

19. Kennedy JM, ZochodneDW. Influence of experimental diabetes on the microcirculation of injured peripheral nerve: functional and morphological aspects. Diabetes. 2002; 51:2233-40.

20. Kennedy JM, ZochodneDW. Experimental diabetic neuropathy with spontaneous recovery: Is there irreparable damage? Diabetes. 2005; 54:830-7.

21. Obrosova IG, Li F, Abatan OI, Forsell MA, Komjáti K, Pacher P, Szabó C, Stevens MJ. Role of Poly (ADP-Ribose) Polymerase activation in diabetic neuropathy. Diabetes. 2004; 53:711-20.

22. Prince AS, Agthong S, Middlemas AB, Tomlinson DR. Mitogenactivated protein kinase p38 mediates reduced nerve conduction velocity in experimental diabetic neuropathy. Diabetes. 2004; 53:1851-6.

23. Snow LM, Sanchez AO, McloonLK, Serfass RC, Thompson LV. Effect of endurance exercise on myosin heavy chain isoform expression in diabetic rats with peripheral neuropathy. Am J Phys Med Rehabil. 2005; 84:770-9.

24. King RHM. The role of glycation in the pathogenesis of diabetic polyneuropathy. J ClinPatholMolPathol. 2001; 54:400-8.

25. Kennedy J.M., ZochodneD.W. Impaired peripheral nerve regeneration in diabetes mellitus. J. Peripher. Nerv. Syst. 2005; 10:144-157.

26. Kennedy J.M., ZochodneD.W. The regenerative deficit of peripheral nerves in experimental diabetes: its extent, timing and possible mechanisms. Brain. 2000; 123:2118-2129. 
27. Jolivalt CG et al. Impaired prosaposin secretion during nerve regeneration in diabetic rats and protection of nerve regeneration by a prosaposin-derived peptide. J NeuropatholExp Neurol. 2008 Jul; 67(7):702-10.

28. Kou ZZ et al. Alterations in the neural circuits from peripheral afferents to the spinal cord: possible implications for diabetic polyneuropathy in streptozotocin-induced type 1 diabetic rats. Front Neural Circuits. 2014 Jan 29; 8:6.

29. Tesfaye S, BoultonAJM, DyckPJ, Freeman R, Horowitz $M$, Kempler P, Lauria G, Malik RA, Spallone V, Vinik A, Bernardi L, Valensi P (2010) Diabetic neuropathies: update on definitions, diagnostic criteria, estimation of severity, and treatments. Diabetes Care 33(10):2285-2293

30. Mizisin AP, Nelson RW, Sturges BK, Vernau KM, Lecouteur RA, Williams DC, Burgers ML, Shelton GD (2007) Comparable myelinated nerve pathology in feline and human diabetes mellitus. ActaNeuropathol 113(4):431-442

31. Quattrini C, Tavakoli M, Jeziorska M, Kallinikos P, Tesfaye $S$, Finnigan J, Marshall A, BoultonAJM, Efron N, Malik RA (2007) Surrogate markers of small fiber damage in human diabetic neuropathy. Diabetes 56(8):2148-2154

32. Pop-Busui R, Herman WH, Feldman EL, Low PA, Martin CL, Cleary PA, WaberskiBH, LachinJM, Albers JW (2010) DCCT and EDIC studies in type 1 diabetes: lessons for diabetic neuropathy regarding metabolic memory and natural history. CurrDiab Rep 10(4):276-282

33. Tesfaye S, Chaturvedi N, Eaton SEM, Ward JD, Manes C, IonescuTirgoviste C, Witte DR, Fuller JH (2005) Vascular risk factors and diabetic neuropathy. N Engl J Med 352(4):341-350

34. Gregory JA et al. Hypertension-induced peripheral neuropathy and the combined effects of hypertension and diabetes on nerve structure and function in rats. ActaNeuropathol. 2012 Oct; 124(4):561-73.

35. Eaton S. E., Harris N. D., Rajbhandari S. M., Greenwood P., Wilkinson I. D., Ward J. D., et al. (2001). Spinal-cord involvement in diabetic peripheral neuropathy. Lancet 358, 35-36 10.1016/ S0140-6736(00)05268-5.

36. Fischer T. Z., Waxman S. G. (2010). Neuropathic pain in diabetes-evidence for a central mechanism. Nat. Rev. Neurol. 6, 462-466 10.1038/nrneurol.2010.90.

37. Todd A. J. (2010). Neuronal circuitry for pain processing in the dorsal horn. Nat. Rev. Neurosci. 11, 823-836 10.1038/nrn2947.

38. Duce I. R., Keen P. (1977). An ultrastructural classification of the neuronal cell bodies of the rat dorsal root ganglion using zinc iodide-osmium impregnation. Cell Tissue Res. 185, 263-277 10.1007/bf00220670.

39. Britland ST, Young RJ, Sharma AK, Clarke BF (1990) Association of painful and painless diabetic polyneuropathy with different patterns of nerve fiber degeneration and regeneration. Diabetes 39:898-908
40. Llewelyn JG, GilbeySG, Thomas PK, King RH, Muddle JR, Watkins PJ (1991) Sural nerve morphometry in diabetic autonomic and painful sensory neuropathy. A clinicopathological study. Brain 114(Pt 2):867-892.

41. Bradley JL, Thomas PK, King RH, Muddle JR, Ward JD, Tesfaye S, BoultonAJ, Tsigos C, Young RJ (1995) Myelinated nerve fibre regeneration in diabetic sensory polyneuropathy: correlation with type of diabetes. ActaNeuropathol 90:403-410

42. Malik RA (1997) The pathology of human diabetic neuropathy. Diabetes 46(Suppl. 2):S50-S53.

43. Chen D, Wang MW (2005) Development and application of rodent models for type 2 diabetes. Diabetes ObesMetab 7:307317.

44. Tan AM, Samad OA, Fischer TZ, Zhao P, Persson AK, Waxman SG (2012) Maladaptive dendritic spine remodeling contributes to diabetic neuropathic pain. J Neurosci 32:6795-6807

45. Woolf CJ, Shortland P, Coggeshall RE (1992) Peripheral nerve injury triggers central sprouting of myelinated afferents. Nature 355:75-78.

46. Woolf CJ, Shortland P, Reynolds M, Ridings J, Doubell T, Coggeshall RE (1995) Reorganization of central terminals of myelinated primary afferents in the rat dorsal horn following peripheral axotomy. J Comp Neurol 360:121-134.

47. Nakamura, H., Domon, Y., Inoue, T., Arakawa, N., \& Yokoyama, T. (2009). Olmesartanmedoxomil ameliorates sciatic nerve regeneration in diabetic rats. Neuroreport, 20, 1481-1485.

48. Federici, T., \&Boulis, N.M. (2009). Invited review: Festschrift edition of neurosurgery peripheral nervous system as a conduit for delivering therapies for diabetic neuropathy, amyotrophic lateral sclerosis, and nerve regeneration. Neurosurgery, 65, A87-A92

49. Piao, Y., \& Liang, X. (2012). Chinese medicine in diabetic peripheral neuropathy: Experimental research on nerve repair and regeneration. Evid Based Complement Alternat Med, 2012, 191632.

50. Weintraub, M.I., Herrmann, D.N., Smith, A.G., Backonja, M.M., \& Cole, S.P. (2009). Pulsed electromagnetic fields to reduce diabetic neuropathic pain and stimulate neuronal repair: A randomized controlled trial. Arch Phys Med Rehabil, 90, 11021109

51. Bril, V. (2012). Treatments for diabetic neuropathy. J PeripherNervSyst, 17, 22-27

52. Yao, C.H., Chang, R.L., Chang, S.L., Tsai, C.C., Tsai, F.J., \& Chen, Y.S. (2012). Electrical stimulation improves peripheral nerve regeneration in streptozotocin-induced diabetic rats. J Trauma AcuteCareSurg, 72, 199-205.

53. Bhadra, N., \&Peckham, P.H. (1997). Peripheral nerve stimulation for restoration of motor function. J ClinNeurophysiol, 14, 378393. 
54. Lin YC. Current-modulated electrical stimulation as a treatment for peripheral nerve regeneration in diabetic rats. RestorNeurolNeurosci. 2014; 32(3):437-46.

55. Tomlinson DR, Gardiner NJ (2008) Glucose neurotoxicity. Nat Rev Neurosci 9(1):36-45

56. Bianchi R, Buyukakilli B, Brines M, Savino C, Cavaletti G, Oggioni N, Lauria G, Borgna M, Lombardi R, Cimen B, Comelekoglu U, Kanik A, Tataroglu C, Cerami A, Ghezzi P (2004) Erythropoietin both protects from and reverses experimental diabetic neuropathy. ProcNatlAcadSci USA 101(3): 823-828

57. Kennedy WR, Wendelschafer-Crabb G, Johnson T (1996) Quantitation of epidermal nerves in diabetic neuropathy. Neurology 47(4):1042-1048

58. Britland ST, Sharma AK, Duguid IG, Thomas PK (1985) Ultrastructural observations on myelinated fibres in the tibial nerve of streptozotocin-diabetic rats: effect of insulin treatment. Life Support Syst 3(Suppl 1):524-529

59. Calcutt NA, CampanaWM, Eskeland NL, Mohiuddin L, Dines KC, Mizisin AP, O'Brien JS (1999) Prosaposin gene expression and the efficacy of a prosaposin-derived peptide in preventing structural and functional disorders of peripheral nerve in diabetic rats. J NeuropatholExpNeurol 58(6):628-636

60. Jakobsen J (1976) Axonal dwindling in early experimental diabetes. I. A study of cross sectioned nerves. Diabetologia 12(6): 539-546

61. Eckersley L (2002) Role of the Schwann cell in diabetic neuropathy. Int Rev Neurobiol 50:293-321

62. Calcutt NA, Muir D, Powell HC, Mizisin AP (1992) Reduced ciliary neuronotrophic factor-like activity in nerves from diabetic or galactose-fed rats. Brain Res 575(2):320-324

63. Mizisin AP, Calcutt NA, DiStefano PS, Acheson A, Longo FM (1997) Aldose reductase inhibition increases CNTF-like bioactivity and protein in sciatic nerves from galactose-fed and normal rats. Diabetes 46(4):647-652.

64. Sharma AK, Thomas PK (1974) Peripheral nerve structure and function in experimental diabetes. J NeurolSci 23(1):1-15

65. Walker D, Carrington A, Cannan SA, Sawicki D, Sredy J, BoultonAJ, Malik RA (1999) Structural abnormalities do not explain the early functional abnormalities in the peripheral nerves of the streptozotocin diabetic rat. J Anat 195(Pt 3):419427

66. Sima AA, Zhang W, Xu G, Sugimoto K, Guberski D, Yorek MA (2000) A comparison of diabetic polyneuropathy in type II diabetic BBZDR/Wor rats and in type I diabetic BB/Wor rats. Diabetologia 43(6):786-793

67. Behse F, Buchthal F, Carlsen F (1977) Nerve biopsy and conduction studies in diabetic neuropathy. J Neurol Neurosurg Psychiatry 40(11):1072-1082

68. Kalichman MW, Powell HC, Mizisin AP (1998) Reactive, degenerative, and proliferative Schwann cell responses in experimental galactose and human diabetic neuropathy. ActaNeuropathol 95(1):47-56
69. Mizisin AP, Powell HC (1993). Schwann cell injury is attenuated by aldose reductase inhibition in galactose intoxication. J NeuropatholExpNeurol 52(1):78-86

70. Eckersley L (2002). Role of the Schwann cell in diabetic neuropathy. Int Rev Neurobiol 50:293-321

71. Cameron NE, Cotter MA, Low PA (1991) Nerve blood flow in early experimental diabetes in rats: relation to conduction deficits. Am J Physiol 261(1 Pt 1):E1-E8

72. Calcutt NA, Mizisin AP, Kalichman MW (1994) Aldose reductase inhibition, Doppler flux and conduction in diabetic rat nerve. Eur J Pharmacol 251(1):27-33

73. Tuck RR, Schmelzer JD, Low PA (1984) Endoneurial blood flow and oxygen tension in the sciatic nerves of rats with experimental diabetic neuropathy. Brain 107:935-950

74. Hendley ED, Cierpial MA, McCarty R (1988) Sympatheticadrenal medullary response to stress in hyperactive and hypertensive rats. PhysiolBehav 44(1):47-51

75. Somani P, Singh HP, Saini RK, Rabinovitch A (1979) Streptozotocininduced diabetes in the spontaneously hypertensive rat. Metabolism 28(11):1075-1077

76. Tsutsu N, Takata Y, Nunoi K, Kikuchi M, Takishita S, Sadoshima S, Fujishima M (1989) Glucose tolerance and insulin secretion in conscious and unrestrained normotensive and spontaneously hypertensive rats. Metabolism 38(1):63-66

77. Tomassoni D, Traini E, Vitaioli L, Amenta F (2004) Morphological and conduction changes in the sciatic nerve of spontaneously hypertensive rats. NeurosciLett 362(2):131-135

78. Bensfield AC, Evans J, Pesayco JP, Mizisin AP, Shelton GD (2011) Recurrent demyelination and remyelination in 37 young bengal cats with polyneuropathy. J Vet Intern Med 25(4):882- 88

79. Hall SM (1983) The response of the (myelinating) Schwann cell population to multiple episodes of demyelination. J Neurocytol 12(1):1-12

80. Behse F, Buchthal (1978) Sensory action potentials and biopsy of the sural nerve in neuropathy. Brain 101(3):473-493

81. Smith KJ, Blakemore WF, Murray JA, Patterson RC (1982) Internodal myelin volume and axon surface area. A relationship determining myelin thickness? J NeurolSci 55(2):231-246

82. Elliott J, Tesfaye S, Chaturvedi N, Gandhi RA, Stevens LK, Emery C, Fuller JH (2009) Large-fiber dysfunction in diabetic peripheral neuropathy is predicted by cardiovascular risk factors. Diabetes Care 32(10):1896-1900

83. Forrest KY, Maser RE, Pambianco G, Becker DJ, Orchard TJ (1997) Hypertension as a risk factor for diabetic neuropathy: a prospective study. Diabetes 46(4):665-670

84. Harris M, Eastman R, Cowie C (1993) Symptoms of sensory neuropathy in adults with NIDDM in the US population. Diabetes Care 16(11):1446-1452 
85. JarmuzewskaEA, Ghidoni A, Mangoni AA (2007) Hypertension and sensorimotor peripheral neuropathy in type 2 diabetes. EurNeurol 57(2):91-95

86. Maser RE, Steenkiste AR, Dorman JS, Nielsen VK, Bass EB, Manjoo Q, Drash AL, Becker DJ, KullerLH, Greene DA (1989) Epidemiological correlates of diabetic neuropathy. Report from Pittsburgh Epidemiology of Diabetes Complications Study. Diabetes 38(11):1456-1461

87. Vincent AM, Hinder LM, Pop-Busui R, Feldman EL. Hyperlipidemia: a new therapeutic target for diabetic neuropathy. J PeripherNervSyst2009; 14:257- 267

88. Sohn MW, Meadows JL, Oh EH, et al. Statin use and lower extremity amputation risk in nonelderly diabetic patients. J VascSurg2013; 58:1578-1585

89. Xu, G., Pierson, C.R., Murakawa, Y., \&Sima, A.A. (2002). Altered tubulin and neurofilament expression and impaired axonal growth in diabetic nerve regeneration. J NeuropatholExpNeurol, 61, 164-175.

90. Zochodne, D.W., Guo, G.F., Magnowski, B., \&Bangash, M. (2007). Regenerative failure of diabetic nerves bridging transection injuries. Diabetes Metab Res Rev, 23, 490-496

91. Karino, K., Nabika, T., Nishiki, M., lijima, K., Nagai, A., \&Masuda, J. (2009). Evaluation of diabetic neuropathy using the tone-entropy analysis, a noninvasive method to estimate the autonomic nervous function. Biomed Res, 30, 1-6.

92. Morimoto, J., Suzuki, Y., Tada, A., Akui, M., Ozawa, Y., \&Maruyama, T. (2012). Time-course changes in nerve conduction velocity (NCV) in type 2 diabetes. J Diabetes Complications, 26, 237-240

93. Malysz, T., Ilha, J., Nascimento, P.S., De Angelis, K., Schaan, B.D., \&Achaval, M. (2010). Beneficial effects of treadmill training in experimental diabetic nerve regeneration. Clinics (Sao Paulo), 65, 1329-1337.

Publish in International Archives of Medicine

International Archives of Medicine is an open access journal publishing articles encompassing all aspects of medical science and clinical practice. IAM is considered a megajournal with independent sections on all areas of medicine. IAM is a really international journal with authors and board members from all around the world. The journal is widely indexed and classified Q2 in category Medicine. 